\title{
A Brief View of the Surface Membrane Proteins from Trypanosoma cruzi
}

\author{
Ángel de la Cruz Pech-Canul, ${ }^{1}$ Victor Monteón, ${ }^{2}$ and Rosa-Lidia Solís-Oviedo ${ }^{1,2}$ \\ ${ }^{1}$ Centre for Biomolecular Sciences, The University of Nottingham, University Park, University Blvd, Nottingham NG7 2RD, UK \\ ${ }^{2}$ Investigaciones Biomédicas, Universidad Autónoma de Campeche, Av. Patricio Trueba s/n, Col. Lindavista, \\ 24039 Campeche, CAM, Mexico
}

Correspondence should be addressed to Rosa-Lidia Solís-Oviedo; solisoviedo@gmail.com

Received 12 January 2017; Revised 31 March 2017; Accepted 27 April 2017; Published 5 June 2017

Academic Editor: José F. Silveira

Copyright (c) 2017 Ángel de la Cruz Pech-Canul et al. This is an open access article distributed under the Creative Commons Attribution License, which permits unrestricted use, distribution, and reproduction in any medium, provided the original work is properly cited.

Trypanosoma cruzi is the causal agent of Chagas' disease which affects millions of people around the world mostly in Central and South America. T. cruzi expresses a wide variety of proteins on its surface membrane which has an important role in the biology of these parasites. Surface molecules of the parasites are the result of the environment to which the parasites are exposed during their life cycle. Hence, T. cruzi displays several modifications when they move from one host to another. Due to the complexity of this parasite's cell surface, this review presents some membrane proteins organized as large families, as they are the most abundant and/or relevant throughout the T. cruzi membrane.

\section{Introduction}

Trypanosoma cruzi is a protozoan causative of Chagas' disease, a pathology characterized by two phases: acute and chronic; both could be asymptomatic. The acute phase is present during the first weeks of infection and the chronic phase includes an indeterminate asymptomatic form and a chronic inflammation associated with myocarditis, heart failure, and megaviscera (megaesophagus and/or megacolon) $[1,2]$. T. cruzi has infected millions of people in the world, mostly in Central and South America; the infection could be via triatomine insect vector, congenital transmission, organ transplantation, or blood transfusion $[3,4]$. The life cycle of $T$. cruzi comprises several morphological transformations involving both mammalian and insect hosts, where three different major developmental stages are identified: epimastigotes, trypomastigotes, and amastigotes (Figure 1) $[5,6]$. The developmental stages of T. cruzi alternate between noninfective and infective forms. Epimastigote and amastigote are noninfective but replicative stages in the gut of the insect vector and inside the mammalian cell, respectively. Trypomastigote stage is infective but nonreplicative and can be also considered as two different developmental stages: the bloodstream trypomastigotes, found in the blood of the vertebrate host, and the metacyclic trypomastigotes, found in the rectum of the insect vector [6-9]. If one considers that the cycle starts with insect sucking the blood of mammalian host infected with the bloodstream trypomastigotes, the ingested trypomastigotes transform into epimastigotes inside the insect stomach and replicate intensely in the midgut. After that, metacyclic trypomastigotes arise from epimastigotes in the hindgut of the insect host which are eliminated with the faeces $[6,10]$. When the insect vector takes a blood meal from a new noninfected host it subsequently defecates in the area near the puncture wound. The infection usually takes place through direct inoculation of excreted metacyclic trypomastigote which forms into the lesioned skin caused by the insect vector bite. Once inside the mammalian host, the metacyclic trypomastigote forms invade the host cells at the inoculation site and transform into the replicative amastigote form. Upon completion of a replicative cycle as intracellular amastigotes, they transform back into bloodstream trypomastigote forms which burst the eukaryotic cell host and are capable of infecting other cells or travel into the bloodstream 


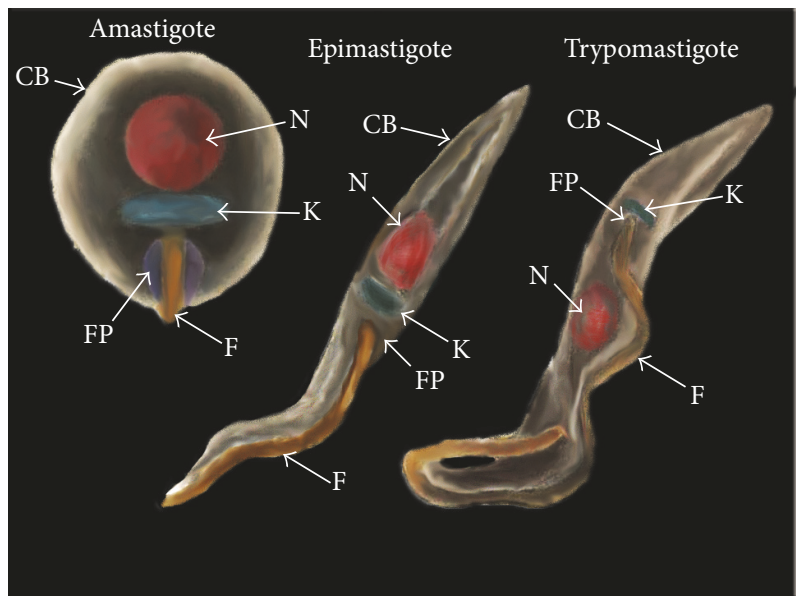

Figure 1: The different stages of Trypanosoma cruzi. The image depicted the amastigote, epimastigote, and trypomastigote stages from T. cruzi and their membrane domains: nucleus (N); kinetoplast (K); flagellum (F); flagellar pocket (FP); and cell body (CB).

[11]. The phenotypic and genotypic diversity of T. cruzi are well recognized. T. cruzi is partitioned into six discrete typing units (DTUs), TcI-TcVI. For a comprehensive review see $[12,13]$. Despite the fact that many T. cruzi isolates have been described through the years, CL Brener was the reference organism used in the "Trypanosoma cruzi Genome Project." CL Brener is a clone derived from CL strain belonging to Tc VI lineage and has been thoroughly studied and well characterized [14-16]. The CL Brener genome sequence is now available and became the $T$. cruzi genome reference for other sequencing projects [13, 14, 17]. Moreover, new T. cruzi isolates are still being reported and features such as some of their surface membrane proteins are regularly compared with the CL Brener genome [17-20]. Although T. cruzi has several morphological transformations through its complex life cycle, studies on surface proteins have been mainly focused on the different stages through the infection process (Figure 1) [21-23]. Membrane proteins have been shown to play an important role in the biology of T. cruzi, including the interaction between parasite and host $[2,22$, 24-28]. Scientists have made efforts to unravel the gaps on the structure and functions of these surface membrane proteins. However, despite their importance, the information is currently scattered. The aim of this review is to outline the families of surface membrane proteins from T. cruzi which are the most abundant and/or relevant during its life cycle (Table 1).

\section{Mucin Family}

Trypanosoma cruzi is covered by a dense layer of mucintype molecules. Mucins are the major T. cruzi surface glycoproteins and their sugar residues are able to interact with mammalian cells $[26,63]$. These proteins are characteristic and widely distributed over the cell body, flagellum, and flagellar pocket of the different developmental forms (Figure 1) [64]. Mucins play a key role in the parasite protection as well as in the infectivity and modulation of the host immune response throughout the T. cruzi life cycle $[25,30,60,65,66]$. Based on sequence comparisons, T. cruzi mucins have been split into two gene families, termed TcMUC and TcSMUG (Figure 2, Table 1) [30, 67]. TcMUC expression seems to be restricted to the mammal-dwelling stages; these proteins are divided into three groups based on their central domains: TcMUC I to III $[67,68]$. TcMUC I and II proteins are distributed on the amastigote and the bloodstream trypomastigote surface. TcMUC I is the major component in the amastigote form, whereas TcMUC II is predominant in membrane lipid rafts of the trypomastigote stage [31]. TcMUC I proteins show internal tandem repeats on their structure with a $\mathrm{T}_{8} \mathrm{KP}_{2}$ amino acid (aa) consensus sequence which are suitable targets for the O-glycosylation pathway in T. cruzi, flanked by an N-terminal signal peptide and a C-terminal glycosylphosphatidylinositol- (GPI-) anchor signal $[30,69]$. TcMUC II genes encode proteins that share similar $\mathrm{N}$ - and C-termini with TcMUC I but without the $\mathrm{T}_{8} \mathrm{KP}_{2}$ motifs, although their central regions are still rich enough in threonine, serine, and proline residues [29, 70]. The single gene product of the TcMUC III group is termed trypomastigote small surface antigen (TSSA) and has been identified as a mucin-like glycoprotein (tGPI-mucins) [71]. TSSA are displayed on the surface of the trypomastigote forms of Trypanosoma cruzi and they are expressed in vivo as $\mathrm{a} \sim 20$ - $\mathrm{kDa}$ protein during the mammal-derived stages [7274].

The second mucin family TcSMUG encodes for very small open reading frame containing a putative signal peptide at the N-terminus and a GPI-anchor signal in the C-terminus. This protein family is divided into two groups: small (S) and large (L) according to their encoded mRNA size [67, 71, 75]. The $\mathrm{S}$ group encodes for $35-50 \mathrm{kDa}$ mucins N-glycosylated (Gp35/50 mucins) and they are the major acceptors of sialic acid on the parasite surface by parasite trans-sialidases in T. cruzi. This $\mathrm{S}$ group is found in the epimastigote and metacyclic trypomastigote forms [32, 33]. TcSMUG L group, in contrast, encodes for mucin-type glycoconjugates which are not sialic acid acceptors and they are only present in the surface of the epimastigote stage $[34,76]$. Furthermore, depending on the origin of the encoding allele, TcSMUG $\mathrm{L}$ products contain one or two additional N-glycosylation signals between the $\mathrm{N}$-terminal region and the threonine-rich region [34].

\section{Trans-Sialidase Superfamily}

Trypanosoma cruzi trans-sialidases (TS) genes are a large superfamily, which includes 1,430 gene members, including 693 pseudogenes $[14,60]$. Similar to mucins, TS are distributed along the cell body, flagellum, and flagellar pocket of T. cruzi [31, 77]. The TS superfamily is divided into four groups: Groups I to IV (Table 1) [78]. Their sequence similarity and functional properties were used as criteria for classification (Figure 3). Importantly, Group I comprises proteins with trans-sialidase (TS) and/or neuraminidase activities [79]. The TS activity involves the transfer of sialic acid from host glycoconjugates to mainly the parasite mucins 


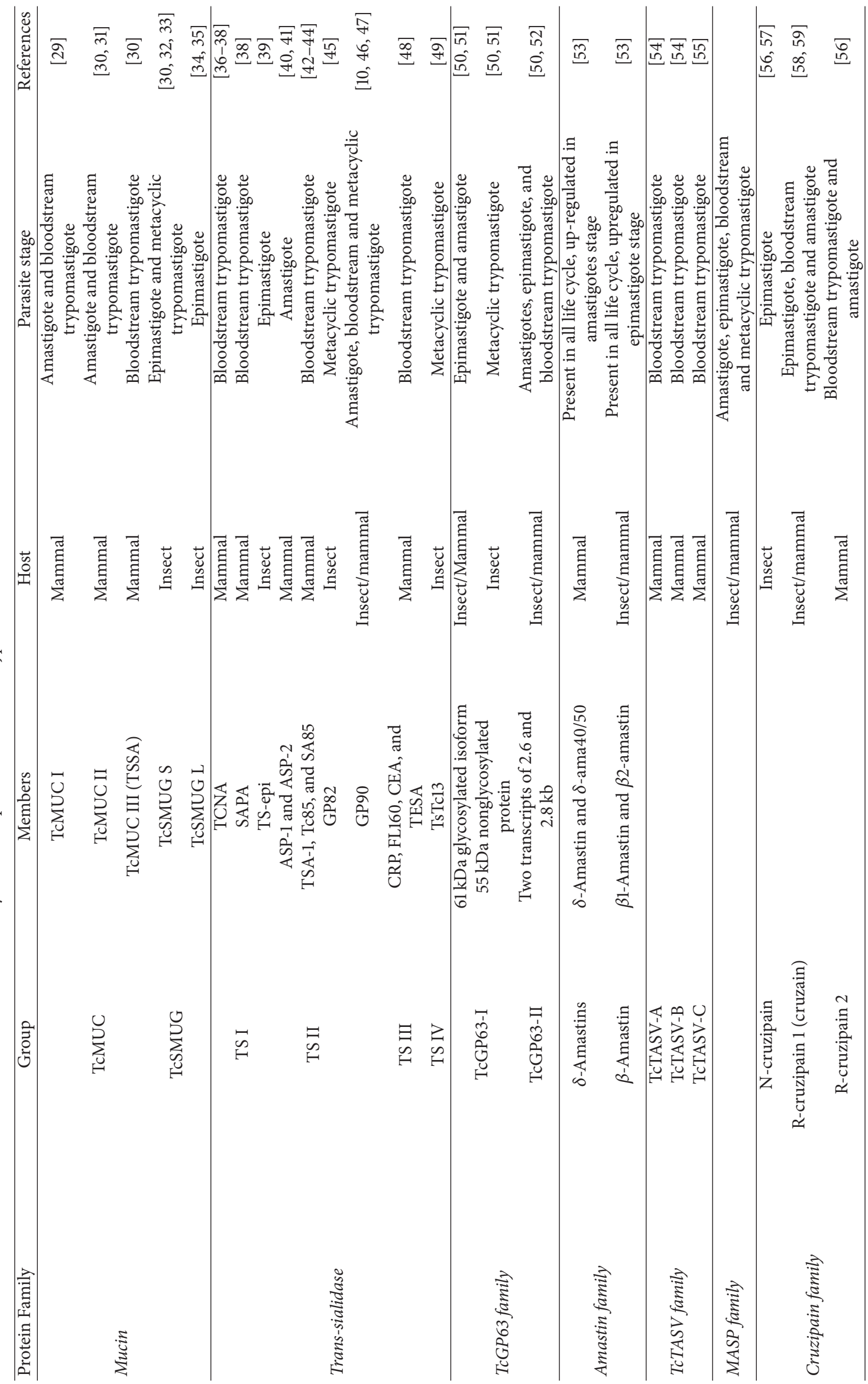


TcMUC in bloodstream trypomastigotes

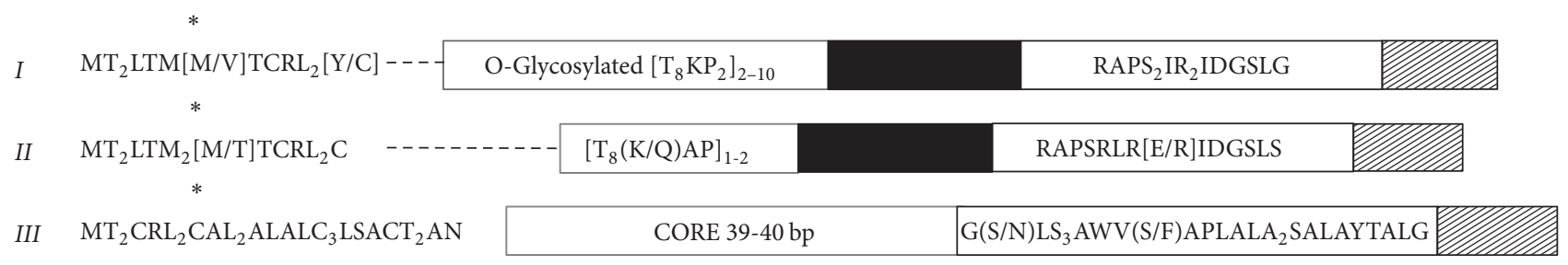

TcSMUG in epimastigotes and metacyclic trypomastigotes

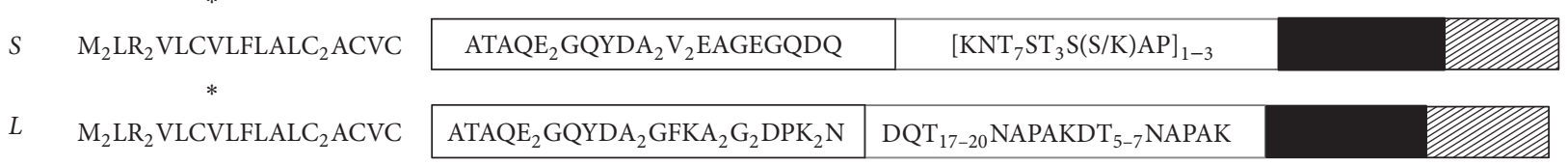

FIGURE 2: Mucin family. Schematic representation of mature proteins of mucin families TcMUC, found in bloodstream trypomastigotes, and TcSMUG, found in epimastigotes and metacyclic trypomastigotes. Signal peptide (*); protein fingerprints (white boxes); hypervariable region (---); threonine-rich region (black boxes) and glycosylphosphatidylinositol- (GPI-) anchor signal (shadowed boxes). Image based on Buscaglia and Frasch $[30,60]$.
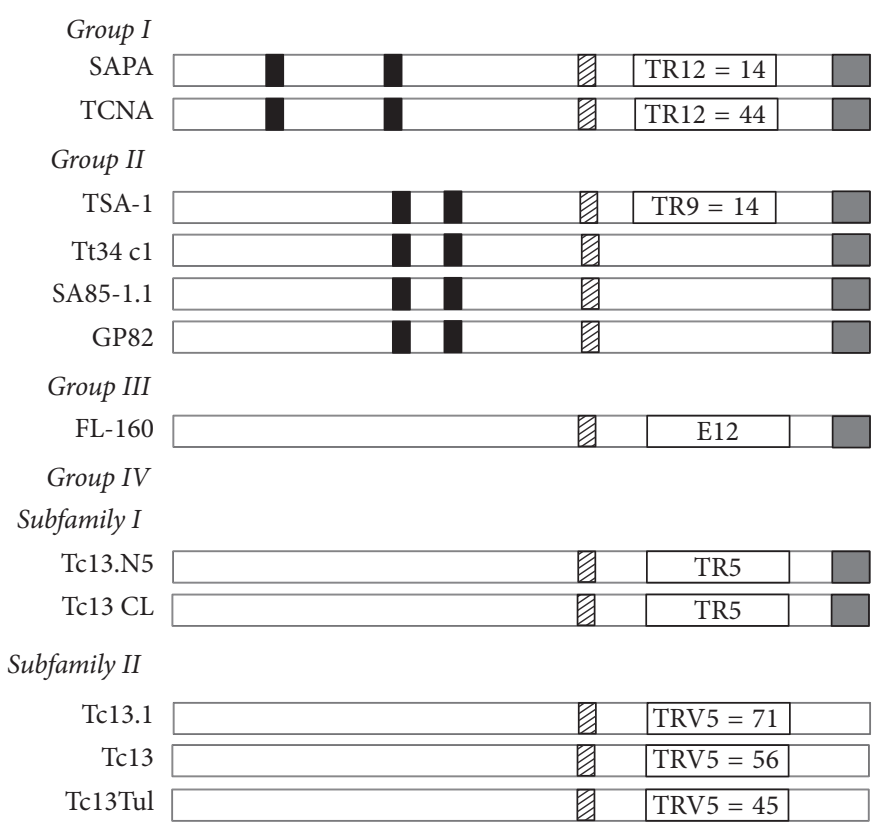

FIGURE 3: Trans-sialidase (TS) superfamily. Schematic representation of the four different groups of trans-sialidases (TS) from Trypanosoma cruzi. Characteristic motifs SXDXGTW and VTVXNVXLYNR for TS are depicted as black and shadowed boxes, respectively. The glycosylphosphatidylinositol- (GPI-) anchor signal in the C-terminus position is shown as grey boxes. Tandem repeats (TR) of 12 amino acid residues $\left[\mathrm{DS}_{2} \mathrm{AH}(\mathrm{S} / \mathrm{G}) \mathrm{TPSTP}(\mathrm{A} / \mathrm{V})\right]$ are detected in SAPA and TCNA (TR12 inside an open box). Nine amino acid residue repeats [DK ${ }_{2}$ ESESGDSE] are identified in TSA-1 (TR9 inside an open box). A characteristic epitope [TPQRKT 2 EDRPQ] is present in FL-160 (E12 inside an open box). The pentapeptide [EPKSA] is found once into subfamily I of Group IV (TR5 inside an open box) whereas, in subfamily II, EPKSA is repeatedly present (TRV5 inside an open box indicating the number of repeats). Image based on Colli and Schenkman [61, 62].

present in the plasma membrane of trypomastigotes [8082]. On the other hand, neuraminidase activity occurs when nonsuitable acceptor molecules for sialic acid are present, and then sialic acid is transferred to water [83]. Trypanosomes are unable to synthesize the monosaccharide sialic acid; they need to scavenge it from the infected host using these TS activities. Therefore the sialylation process in T. cruzi is crucial for its viability and propagation into the host [84-87]. Moreover, neuraminidase activity was proposed to be involved in the removal of sialic acid from parasites and/or host-cell molecules which is required for parasite internalization $[84,88]$. TS Group I members are as follows: TCNA (neuraminidase), SAPA (shed acute-phase antigen), and TS-epi (Figure 3) [36, 37, 61]. SAPA and TCNA enzymes 
have active trans-sialidase and neuraminidase activities and are expressed during bloodstream trypomastigote stage [38]. Both enzymes are very close related; when compared they have $84 \%$ homology at the aa level. SAPA and TCNA have two main regions: an $\mathrm{N}$-terminal catalytic region and a Cterminal extension, which repeats 12 amino acids (SAPA repeats) in tandem with the consensus sequence: D-S-S-AH-[S/G]-T-P-S-T-P-[A/V] [89]. SAPA has only 14 tandem repeats compared to 44 for TCNA. The presence of SAPA repeats increases the half-life of the protein in the blood [90]. Both SAPA and TCNA proteins are anchored by glycosylphosphatidylinositol (GPI) to the parasite plasma membrane and can be found in serum from deeply infected mammals [38, 82]. Recently, Lantos and coworkers have shown that domains for mucins and TS are separated by about $150 \mathrm{~nm}$, indicating that mucins do not pass through a TS-rich area for sialylation [31]. Moreover, they proposed a mechanism for the shedding of trans-sialidase into the extracellular space and/or bloodstream via microvesicles, where the phosphatidylinositol-phospholipase-C activity is actually not present in bloodstream trypomastigote stage [31]. TS-epi, the third member of Group I, is an active transsialidase expressed in the insect dwelling epimastigote form at the stationary phase and is different from the TS expressed of the blood trypomastigotes. TS-epi lacks SAPA repeats and is not anchored to the membrane by GPI; instead it is predicted that anchoring to the membrane is due to the presence of a transmembrane domain followed by a hydrophilic section in the C-terminus [39]. That last feature may explain why TS-epi is minimally secreted into the medium [91].

TS Group II comprises members of the GP85 surface glycoproteins: ASP-1, ASP-2, TSA-1, Tc85, SA85, GP82, and GP90. They all have been implicated in host-cell attachment and invasion [62, 92-94]. These proteins have complete or degenerate Asp box motifs (SxDxGxTW); the VTVxNVxLYNR motif characteristic of all TS members; and a signal sequence for cleavage/addition of GPI anchor at the C-terminal region (Figure 3) [60, 62, 95]. ASP-1, ASP-2, and TSA- 1 are targets of T. cruzi-specific $\mathrm{CD}^{+}$cytotoxic $\mathrm{T}$ lymphocytes and they induce strong antibody responses in infected mice and humans $[40,41,96,97]$. ASP-1 and ASP-2 are amastigote surface proteins, whereas TSA-1 is a trypomastigote surface antigen [40, 41]. SA85 glycoproteins are expressed by amastigote and bloodstream trypomastigote forms. However, only the amastigote form expresses the mannose-binding protein ligand which seems to be involved in the opsonization of the parasite enhancing its infection capability [98-100]. The Tc 85 molecule is an $85 \mathrm{kDa}$ glycoprotein and is found abundantly in bloodstream trypomastigotes. Tc85 is identified as a ligand capable of binding to different host receptor molecules (cytokeratin 18, fibronectin, and laminin) located on the cell surface of either monocytes, neutrophils, or fibroblasts [42, 92, 101, 102]. Furthermore, GP82 and GP90 are glycoproteins expressed on the surface of the metacyclic trypomastigote form [46, 103], and they are found mainly at the plasma membrane with opposite roles in mammalian cell invasion [33, 46]. GP82 is able to activate a $\mathrm{Ca}^{2+}$ signaling pathway in host cells following parasite adhesion, which is required for T. cruzi internalization [101,
104-106]. GP82 binds less efficiently to HeLa cells compared to GP90, but it is capable of triggering the $\mathrm{Ca}^{2+}$ signal in that host cell [105]. GP82 is also the signaling receptor that mediates protein tyrosine phosphorylation, which is necessary for host-cell invasion [106]. On the other hand, GP90 is a metacyclic stage-specific glycoprotein defined by its reactivity with monoclonal antibodies 1G7 and 5E7 [46]. GP90 expressed by metacyclic forms lacks any enzymatic activity [47]. GP90 is also present in the mammalian stages of T. cruzi (bloodstream trypomastigote and amastigotes stages) and has the antiphagocytic effect mediated by the removal of sugar residues necessary for parasite internalization. This surface glycoprotein appears to have glycosidase activity and downregulates host-cell invasion probably due to the fact that GP90 binds to mammalian cells in a receptor-mediated manner without triggering the $\mathrm{Ca}^{2+}$ signal-inducing activity $[10,47]$.

TS Group III is formed by surface proteins present in mammal-dwelling blood trypomastigotes which include the following: CRP, FL160, CEA, and TESA [48]. These proteins are recognized by sera from patients with Chagas' disease and they are able to inhibit the classical and the alternative pathways of complement activation, which could be a protection from lysis by the host in the trypomastigote form [48, $62,95,107-109]$. TESA (trypomastigote excretory-secretory antigens) is distributed on the cell surface membrane of $T$. cruzi $[107,110]$ whereas CRP, FL160, and CEA are flagellumassociated membrane proteins [111-113]. Interestingly, the sequence of FL-160 contains an epitope which molecularly mimics a nervous tissue antigen from the mammalian host [114].

Finally, TS Group IV is composed of genes encoding trypomastigote surface antigens whose biological function is still unknown. This group is included in the TS superfamily because it contains the conserved motif VTVxNVxLYNR, which is shared by all known TS members $[10,37,54,61,115]$. However, the B5 peptide from TsTc13 protein, a representative of Group IV, has been shown to be highly antigenic and is present in the infective metacyclic trypomastigote form [49].

\section{TcGP63 Family}

Trypanosomes and Leishmania species express a family of cell surface-localized, zinc-dependent metalloproteases, which are also termed as GP63 proteins, major surface proteases, or leishmanolysins. Metallopeptidase activities have been described in trypanosomatids [116-118], but only the socalled GP63 from Leishmania spp. has been thoroughly characterized. Trypanosoma cruzi possesses GP63-like genes (TcGP63) and they are differentially regulated, which suggests its functional importance at multiple stages in the parasite life cycle [52, 119, 120]. The TcGP63 family has at least two groups of proteins: TcGP63-I and TcGP63-II (Figure 4, Table 1) [50]. It has been estimated that TcGP63-I has low (5-10) gene copies, whereas TcGP63-II has 62 gene copies into the T. cruzi genome [50,51]. The TcGP63-I group is present in the three life-stages of $T$. cruzi. These proteins present metallopeptidase activity and are bound to the protozoan's membrane by a C-terminal glycosylphosphatidylinositol- 
Tcgp63-I

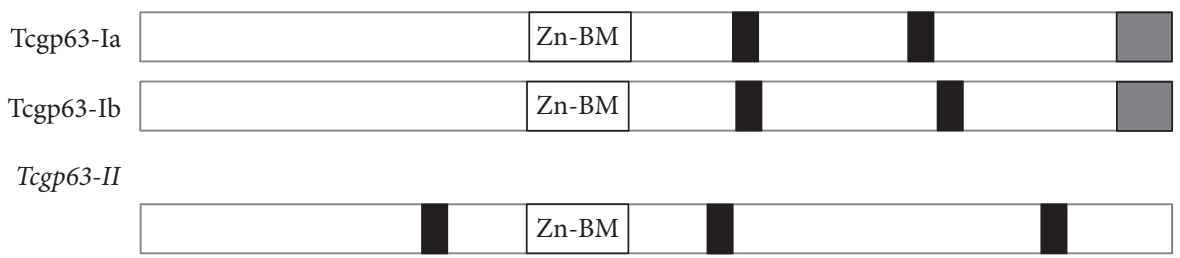

FIgure 4: The TcGP63 family. The TcGP63 family consists of cell surface-localized, zinc-dependent metalloproteases also known as T. cruzi GP63-like proteins. This family has at least two groups: TcGP63-I and TcGP63-II. TcGP63-I members have two potential N-glycosylation sites, whereas TcGP63-II members have three [50]. The glycosylphosphatidylinositol- (GPI-) anchor signal in the C-terminus position is depicted as grey boxes; it is absent in the TcGP63-II members. Predicted N-glycosylation sites are shown in black boxes. Zn-BM: zinc-binding motifs $\left[\mathrm{VXAHEX}_{2} \mathrm{HA}\right]$ associated with metalloprotease activity.

(GPI-) anchor signal [50]. Two isoforms are known of TcGP63-I in T. cruzi: a glycosylated and a nonglycosylated isoform. The $61 \mathrm{kDa}$ glycosylated isoform is present in similar levels in both epimastigote and amastigote forms and is irregularly expressed on the surface membranes (cell body and flagellum) of the epimastigote. The second isoform is a $55 \mathrm{kDa}$ TcGP63 nonglycosylated protein, which is located intracellularly near the kinetoplast and the flagellar pocket of the metacyclic trypomastigote [52]. TcGP63-II does not have GPI-anchor signal; instead its C-terminal sequence is replaced by a charged region containing three Asp and four Arg residues [50, 52].

\section{Amastin Family}

The amastin family is a group of transmembrane glycoproteins, which consists of small proteins of about 180 amino acids. Phylogenetic analysis of trypanosomatid amastins has defined four subfamilies named $\alpha-, \beta-, \gamma$-, and $\delta$-amastins, with distinct genomic organization as well as patterns of expression during the cell cycle of trypanosomatid [121, 122]. The Trypanosoma cruzi genome possesses two distinct subfamilies: $\beta$ - and $\delta$-amastins (Table 1), which have predicted the occurrence of four transmembrane regions (Figure 5) [53]. Genes encoding for the $\beta 1$ - and $\beta 2$-amastin, belonging to the $\beta$ - subfamily, are localized in the chromosome 32 of T. cruzi, whereas $\delta$-amastin and $\delta$-ama40/50 loci are found on chromosomes 34 and 26, respectively. $\beta 1$ - and $\delta$-amastins are clearly located at the cell surface. Interestingly, $\beta 2$ amastin shows a disperse distribution within the cytoplasm in addition to their surface localization [53]. The exact biological function of amastin is still unknown; however, as transmembrane proteins, amastins could play a role in proton or ion traffic across the membrane [123, 124]. Transcript levels of $\delta$-amastins are upregulated in amastigotes from different $T$. cruzi strains, while $\beta$-amastin transcripts are more abundant in epimastigotes than in amastigotes or trypomastigotes; therefore $\beta$-amastins may be involved in the parasite adaptation to the insect vector $[121,125,126]$. Interestingly, Cruz and coworkers showed that $\delta$-amastin plays a crucial role in the differentiation of T. cruzi; therefore it is a key molecule responsible for the parasite survival in the intracellular cell stage [127].

\section{TcTASV Family}

TcTASV (Trypomastigote Alanine Serine Valine-rich protein) is a family that comprises 40 members in Trypanosoma cruzi. They all have a $\mathrm{C}$ - and an $\mathrm{N}$ - terminus conserved with a variable central core. This variable core is rich in $\mathrm{Ala}$, Ser, and Val residues, with a conserved Glu-Ala-Pro motif. It also has a high number of Ser and Thr susceptible to glycosylation and a signal peptide and a consensus sequence for the addition of a GPI anchor were predicted, suggesting that this family can be located at the parasite surface and/or be secreted to the milieu [54]. The TcTASV family is conserved across the genomes of $T$. cruzi strains and, to date, no orthologues in other trypanosomatids have been found [55].

TcTASV family was split into three subfamilies: A, B, and $\mathrm{C}$ apoproteins, based on their predicted molecular weights (18 kDa, $27 \mathrm{kDa}$, and $36 \mathrm{kDa}$, resp.) (Figure 1) [54]. Until now, only subfamilies A and C have been worked thoroughly. Subfamily B has presented experimental hurdles to overcome. Annotated genes identified as TcTASVs are present in 5 chromosomes; almost all annotated subfamily C on the chromosome 24 and a high proportion of subfamily A on the chromosome 16. A peptide entirely conserved in TcTASV-A is present in trypomastigote and amastigote extract. However, only the expression of TcTASV-A in bloodstream trypomastigotes was demonstrated, suggesting that the TcTASV population could undergo developmental regulation $[54,128]$. The TcTASV-C subfamily is expressed mainly in the trypomastigote stage as a phosphorylated, heavily glycosylated protein with ca. $60 \mathrm{kDa}$. TcTASV-C is attached to the parasite surface by a GPI anchor on the cell body and flagellum, which may explain why it is shed spontaneously into the medium and is in contact with the immune system of the host during the course of the natural infection. The superficial localization and secretory nature of TcTASV-C suggest a possible role in the host-parasite interactions [55].

\section{Mucin-Associated Surface Proteins (MASPs) Family}

This family received its name because its members are located in close proximity of Trypanosoma cruzi mucins (TcMUC 


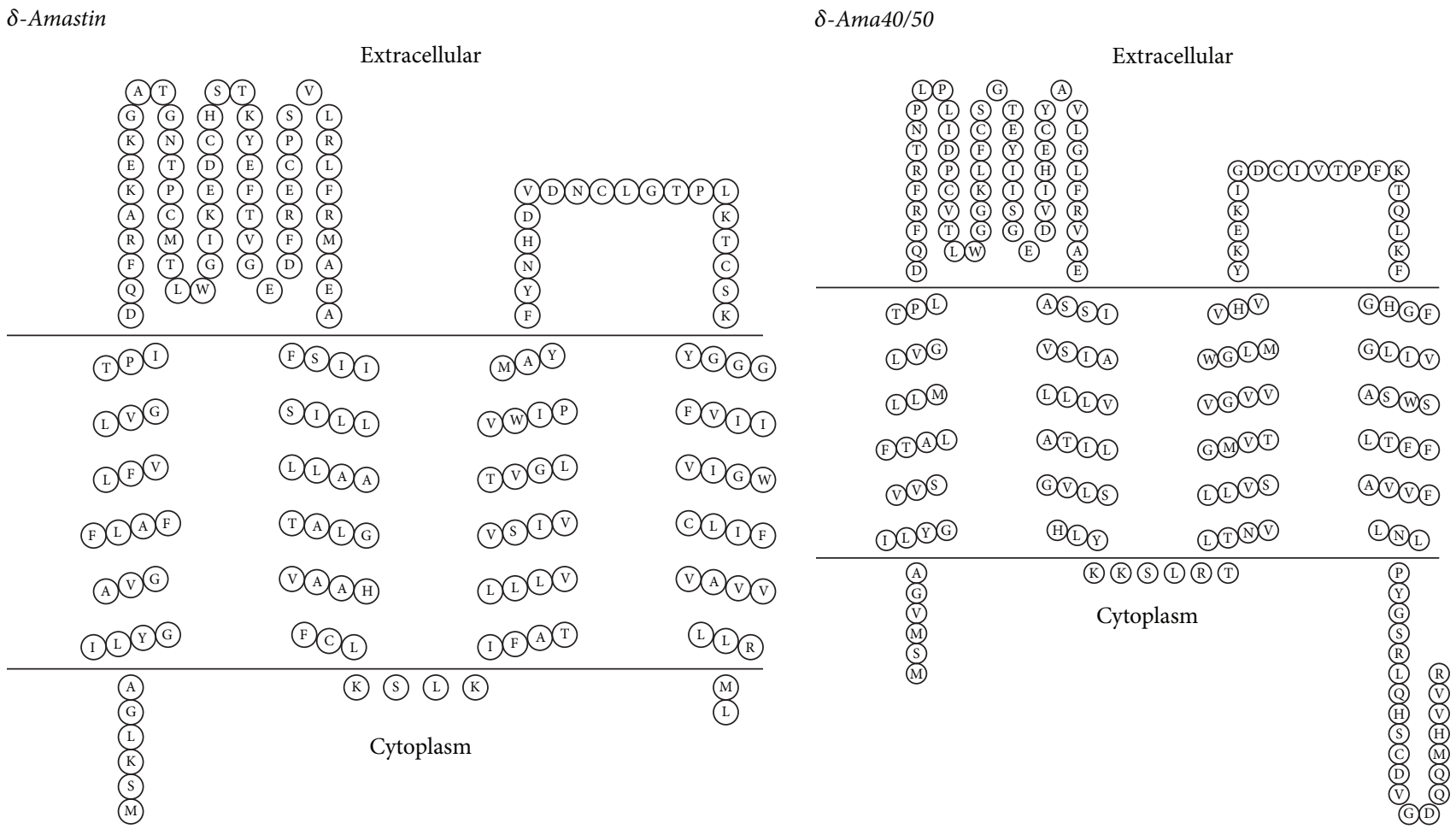

$\beta 1$-Amastin

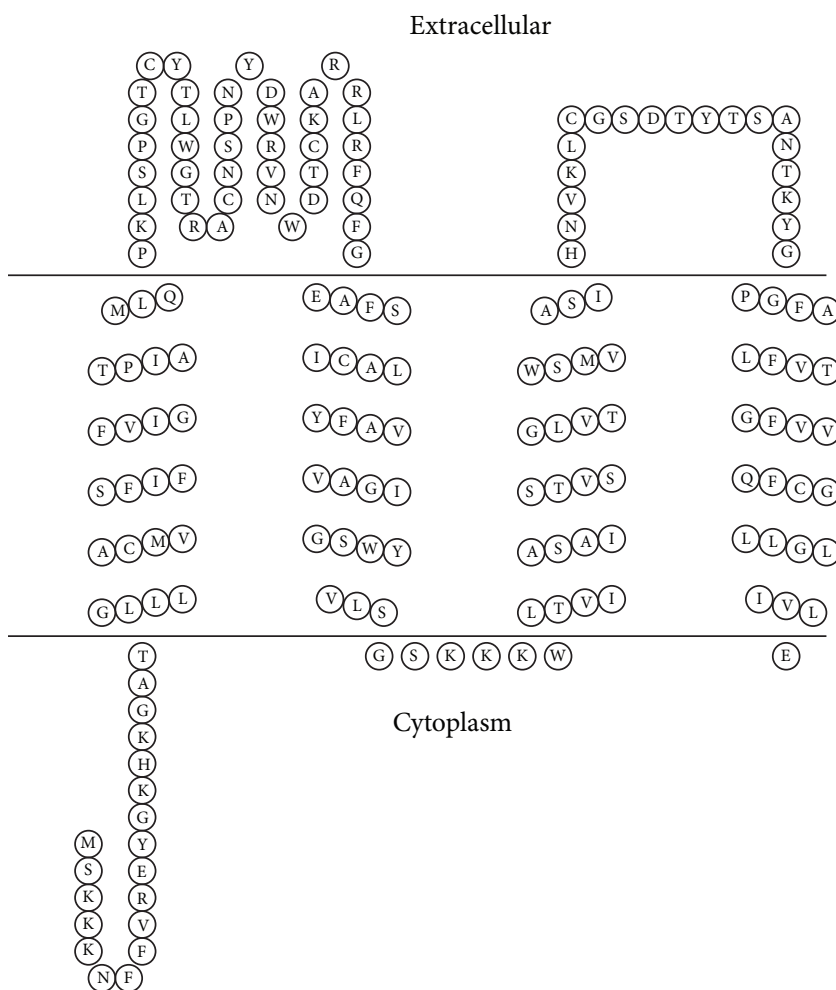

$\beta 2$-Amastin

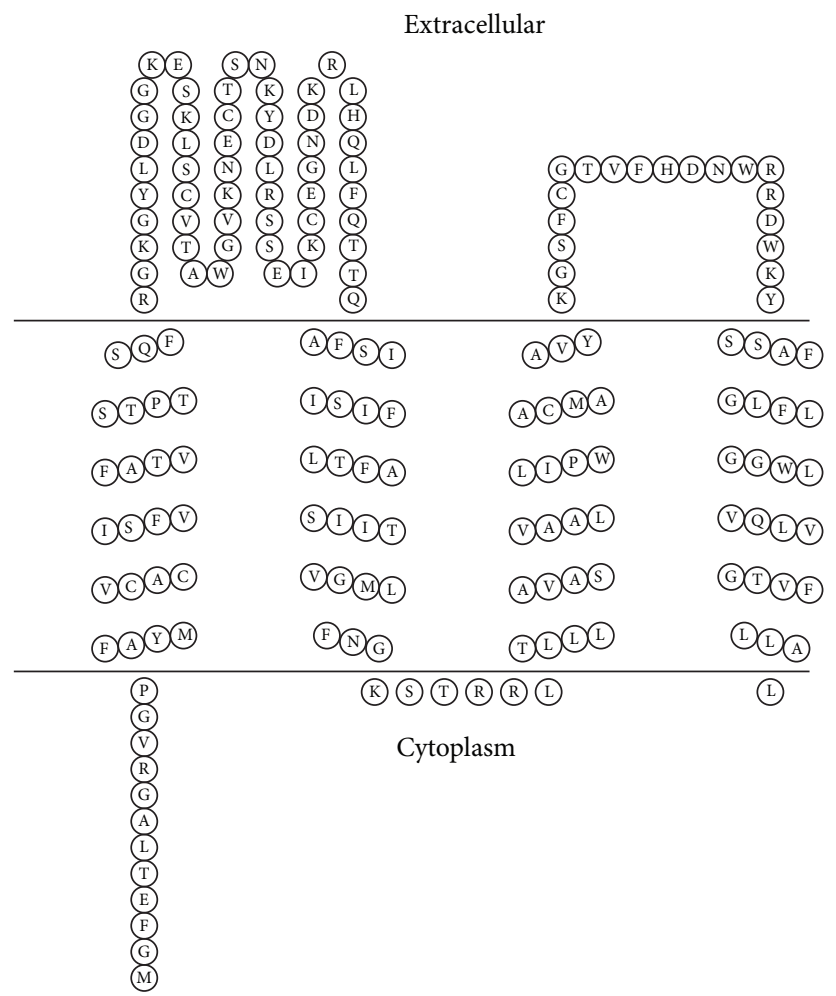

Figure 5: Amastin family. Topological model of subfamilies $\beta$ - and $\delta$-amastins from Trypanosoma cruzi. Amastins models share four predicted transmembrane helices and two extracellular hydrophilic loops. Although both $\mathrm{N}$ - and C-termini are predicted to be facing the cytoplasmic space, their length is variable among them. Topology predictions were performed using the "TOPO2, transmembrane protein display software" (http://www.sacs.ucsf.edu/TOPO2). 
II); they are similar in structure, though not in sequence $[129,130]$. MASP members contain $\mathrm{N}$ - and C-terminal conserved domains that encode a signal peptide and a GPIanchor addition site, respectively. MASP is GPI anchored to the membrane and is preferentially expressed during the trypomastigote (bloodstream) stage (Table 1). Moreover, the central region is variable both in length (ranging 176-645 aa) and in sequence; its sequence also contains a large repertoire of repetitive motifs. Single aa residue repetitions are the most common, and those containing glutamic acid are more frequently being around $27 \%$ of the total of the identified repetitive motifs. Full-length MASP analysis revealed at least four potential O-glycosylation sites per sequence, $70 \%$ of which correspond to threonines [130]. The MASP expression was analyzed throughout the parasite life cycle and it was identified that they are expressed simultaneously in bloodstream trypomastigotes as well as in amastigotes and epimastigotes [45, 128]. MASP molecules are the most abundant antigens found on the surface of the infective trypomastigote stage of T. cruzi [130-133]. The overexpression of MASPs in the intracellular parasites prior to the division of the amastigotes located in the plasma membrane suggests that some of the proteins of this extensive family play a major biological role in the survival and multiplication of intracellular amastigotes $[130,134]$.

\section{Cruzipain Family}

Cruzipains are a papain-like cysteine proteases; cruzipain is expressed as a complex mixture of isoforms in all the Trypanosoma cruzi developmental stages (Figure 1) [135]. Despite the fact that cruzipain has high homology with other members of the papain proteases superfamily, this protein has a unique C-terminal region, which is retained in the mature protein $[136,137]$. Cruzipains are expressed on all the body surface of epimastigotes and amastigotes. In contrast, on the trypomastigote form, cruzipain has only been present in the flagellar pocket region as well as within the pocket [138]. A specific, irreversible enzyme inhibitors for cruzipain GP57/51 was evaluated in heart muscle cells infected with trypomastigotes and proved to interfere with cell invasion and inhibit T. cruzi intracellular replication $[139,140]$. The above suggests that cruzipain plays a role in the process of T. cruzi internalization into mammalian cells [138-140]. Additionally, cruzipain not only is essential for parasite survival but also generates a strong immune response in infected individuals $[138,141]$.

\section{Concluding Remarks}

A tangled mechanism is necessary for a "successful" hostpathogen interaction of Trypanosoma cruzi with its mammalian or insect host. The availability of the T. cruzi genome sequence made it possible to gain new insights into the parasite's biology and allowed the development of new powerful approaches to understand molecular pathogenesis and host-parasite interaction [14]. Proteome analysis was conducted in the different developmental stages of T. cruzi; as expected, surface proteins are part of the outstanding proteins which were found differentially expressed among stages [128]. Another proteomic analysis has also been conducted in different organelles, on a specific developmental stage, or under certain stress conditions [8, 142-144]. Additionally, new technologies are now available to facilitate genome editing in T. cruzi, such as the Cre-recombinases and the CRISPRCas9 system. These genetic manipulation strategies have highly effective efficiency in different organisms and now were successfully adapted to disrupt genes from T. cruzi [145147]. Furthermore the CRISPR-Cas9 system was recently used for endogenous tagging of proteins in T. cruzi which proved that this system is not limited to loss-of-function and made the localization/visualization of proteins from inside the parasite possible [148]. These new molecular strategies have now opened a new field of possibilities towards a more comprehensive functional analysis of the parasite biology and can be potentially used to move forward in the study of surface proteins of T. cruzi. As we present here, several studies show that surface membrane proteins are crucial for adaptation, differentiation, and survival of the parasite during its life cycle. Notably, some membrane protein families stand out during the host-parasite infection process, which make them potential targets to treat, or even prevent, the infection process. Altogether, these recent advancements can positively increase the current knowledge of host-parasite interactions and will help to accelerate the discovery of effective drugs against the Chagas disease. Despite all the research advances on these protein families on T. cruzi membrane, efforts to unravel their structure and function still have a long journey to be undertaken.

\section{Conflicts of Interest}

The authors declare that they have no conflicts of interest.

\section{Acknowledgments}

The authors acknowledges the support from the PROMEP/ 103.5/12/8515 and the National Council of Science and Technology from Mexico (CONACyT). They also thank David Ortega for his careful reading of the manuscript and helpful comments and suggestions. Ángel de la Cruz Pech-Canul and Rosa-Lidia Solís-Oviedo were supported by CONACyT with application nos. 250293 and 250294, respectively.

\section{References}

[1] C. Bern, "Chagas' disease," New England Journal of Medicine, vol. 373, no. 5, pp. 456-466, 2015.

[2] A. E. Balber, "The pellicle and the membrane of the flagellum, flagellar adhesion zone, and flagellar pocket: functionally discrete surface domains of the bloodstream form of African trypanosomes," Critical Reviews in Immunology, vol. 10, no. 3, pp. 177-201, 1990.

[3] L. V. Kirchhoff, "Epidemiology of American trypanosomiasis (Chagas Disease)," Advances in Parasitology, vol. 75, pp. 1-18, 2011.

[4] B. Y. Lee, K. M. Bacon, M. E. Bottazzi, and P. J. Hotez, "Global economic burden of Chagas disease: a computational 
simulation model," The Lancet Infectious Diseases, vol. 13, no. 4, pp. 342-348, 2013.

[5] S. Goldenberg and A. R. Ávila, "Aspects of trypanosoma cruzi stage differentiation," in Advances in Parasitology, H. B. Tanowitz, L. M. Weiss, and L. V. Kirchhoff, Eds., pp. 285-305, Academic Press, Chapter 13 edition, 2011.

[6] W. De Souza, "Basic cell biology of Trypanosoma cruzi," Current Pharmaceutical Design, vol. 8, no. 4, pp. 269-285, 2002.

[7] M. L. Díaz, R. Torres, and C. I. González, "Expresión diferencial entre estadios de Trypanosoma cruzi I en el aislamiento de un paciente con cardiomiopatía chagásica crónica de zona endémica de Santander, Colombia," Biomédica, vol. 31, no. 4, pp. 503-513, 2011.

[8] A. d. C. M. d. Santos Júnior, D. E. Kalume, R. Camargo et al., "Unveiling the trypanosoma cruzi nuclear proteome," PLoS ONE, vol. 10, no. 9, Article ID e0138667, 2015.

[9] R. M. L. Queiroz, S. Charneau, I. M. D. Bastos et al., "Cell surface proteome analysis of human-hosted trypanosoma cruzi life stages," Journal of Proteome Research, vol. 13, no. 8, pp. 35303541, 2014.

[10] W. de Souza, T. M. de Carvalho, and E. S. Barrias, "Review on trypanosoma cruzi: host cell interaction," International Journal of Cell Biology, vol. 2010, article 295394, 18 pages, 2010.

[11] S. M. Teixeira, R. M. C. de Paiva, M. M. Kangussu-Marcolino, and W. D. DaRocha, "Trypanosomatid comparative genomics: contributions to the study of parasite biology and different parasitic diseases," Genetics and Molecular Biology, vol. 35, no. 1, pp. 1-17, 2012.

[12] S. F. Brenière, E. Waleckx, and C. Barnabé, "Over six thousand trypanosoma cruzi strains classified into discrete typing units (dtus): attempt at an inventory," PLOS Neglected Tropical Diseases, vol. 10, no. 8, Article ID e0004792, 2016.

[13] B. Zingales, M. A. Miles, D. A. Campbell et al., "The revised Trypanosoma cruzi subspecific nomenclature: rationale, epidemiological relevance and research applications," Infection, Genetics and Evolution, vol. 12, no. 2, pp. 240-253, 2012.

[14] N. M. El-Sayed, P. J. Myler, D. C. Bartholomeu et al., "The genome sequence of trypanosoma cruzi, etiologic agent of chagas disease," Science, vol. 309, no. 5733, pp. 409-415, 2005.

[15] M. R. M. Santos, M. I. Cano, A. Schijman et al., "The trypanosoma cruzi genome project: nuclear karyotype and gene mapping of clone cl brener," Memórias do Instituto Oswaldo Cruz, vol. 92, no. 6, pp. 821-828, 1997.

[16] W. Degrave, M. J. Levin, J. F. da Silveira et al., "Parasite genome projects and the trypanosoma cruzi genome initiative," Memórias do Instituto Oswaldo Cruz, vol. 92, no. 6, pp. 859-862, 1997.

[17] P. B. Hamilton and J. R. Stevens, "15-Classification and phylogeny of Trypanosoma cruzi A2-Telleria, Jenny," in American Trypanosomiasis Chagas Disease, M. Tibayrenc, Ed., pp. 321344, Elsevier, London, 2nd edition, 2017.

[18] L. A. Shender, M. D. Lewis, D. Rejmanek, and J. A. K. Mazet, "Molecular diversity of trypanosoma cruzi detected in the vector triatoma protracta from california, USA," PLoS Neglected Tropical Diseases, vol. 10, no. 1, Article ID e0004291, 2016.

[19] R. Ruíz-Sánchez, M. P. de León, V. Matta et al., “Trypanosoma cruzi isolates from Mexican and Guatemalan acute and chronic chagasic cardiopathy patients belong to Trypanosoma cruzi I," Memórias do Instituto Oswaldo Cruz, vol.100, no. 3, pp. 281-283, 2005.
[20] V. M. Monteón, R. López, A. A. Ramos-Ligonio, and K. Acosta-Viana, "Trans sialidase genes allow clustering of tci trypanosoma cruzi mexican isolates," British Microbiology Research Journal, vol. 4, no. 12, pp. 1299-1310, 2014.

[21] J. A. Perez-Molina, F. Norman, and R. Lopez-Velez, "Chagas disease in non-endemic countries: epidemiology, clinical presentation and treatment," Current Infectious Disease Reports, vol. 14, no. 3, pp. 263-274, 2012.

[22] K. Gull, "Host-parasite interactions and trypanosome morphogenesis: a flagellar pocketful of goodies," Current Opinion in Microbiology, vol. 6, no. 4, pp. 365-370, 2003.

[23] F. Noireau, P. Diosque, and A. M. Jansen, "Trypanosoma cruzi: adaptation to its vectors and its hosts," Veterinary Research, vol. 40, no. 2, article 26, pp. 1-23, 2009.

[24] C. Gadelha, S. Rothery, M. Morphew, J. R. McIntosh, N. J. Severs, and K. Gull, "Membrane domains and flagellar pocket boundaries are influenced by the cytoskeleton in African trypanosomes," Proceedings of the National Academy of Sciences of the United States of America, vol. 106, no. 41, pp. 17425-17430, 2009.

[25] S. M. Landfear and M. Ignatushchenko, "The flagellum and flagellar pocket of trypanosomatids," Molecular and Biochemical Parasitology, vol. 115, no. 1, pp. 1-17, 2001.

[26] F. Villalta and F. Kierszenbaum, "Host-cell invasion by Trypanosoma cruzi: role of cell surface galactose residues," Biochemical and Biophysical Research Communications, vol. 119, no. 1, pp. 228-235, 1984.

[27] S. Lacomble, S. Vaughan, M. Deghelt, F. F. Moreira-Leite, and K. Gull, "A trypanosoma brucei protein required for maintenance of the flagellum attachment zone and flagellar pocket ER domains," Protist, vol. 163, no. 4, pp. 602-615, 2012.

[28] C. L. Alcantara, J. C. Vidal, W. de Souza, and N. L. Cunhae-Silva, "The three-dimensional structure of the cytostomecytopharynx complex of Trypanosoma cruzi epimastigotes," Journal of Cell Science, vol. 127, no. 10, pp. 2227-2237, 2014.

[29] J. M. Di Noia, D. O. Sanchez, and A. C. C. Frasch, "The protozoan Trypanosoma cruzi has a family of genes resembling the mucin genes of mammalian cells," The Journal of Biological Chemistry, vol. 270, no. 41, pp. 24146-24149, 1995.

[30] C. A. Buscaglia, V. A. Campo, A. C. C. Frasch, and J. M. Di Noia, "Trypanosoma cruzi surface mucins: host-dependent coat diversity," Nature Reviews Microbiology, vol. 4, no. 3, pp. 229236, 2006.

[31] A. B. Lantos, G. Carlevaro, B. Araoz et al., "Sialic acid glycobiology unveils trypanosoma cruzi trypomastigote membrane physiology," PLoS Pathogens, vol. 12, no. 4, Article ID e1005559, 2016.

[32] S. Schenkman, M. A. J. Ferguson, N. Heise, M. L. Cardoso de Almeida, R. A. Mortara, and N. Yoshida, "Mucin-like glycoproteins linked to the membrane by glycosylphosphatidylinositol anchor are the major acceptors of sialic acid in a reaction catalyzed by trans-sialidase in metacyclic forms of Trypanosoma cruzi," Molecular and Biochemical Parasitology, vol. 59, no. 2, pp. 293-303, 1993.

[33] N. Yoshida, "Molecular basis of mammalian cell invasion by Trypanosoma cruzi," Anais da Academia Brasileira de Ciências, vol. 78, no. 1, pp. 87-111, 2006.

[34] I. Urban, L. Boiani Santurio, A. Chidichimo et al., "Molecular diversity of the Trypanosoma cruzi TcSMUG family of mucin genes and proteins," Biochemical Journal, vol. 438, no. 2, pp. 303-313, 2011. 
[35] M. S. Gonzalez, M. S. Souza, E. S. Garcia et al., “Trypanosoma cruzi tcsmug 1-surface mucins promote development and infectivity in the triatomine vector rhodnius prolixus," PLoS Neglected Tropical Diseases, vol. 7, no. 11, Article ID e2552, 2013.

[36] P. Velge, M. A. Ouaissi, J. Cornette, D. Afchain, and A. Capron, "Identification and isolation of Trypanosoma cruzi trypomastigote collagen-binding proteins: possible role in cellparasite interaction," Parasitology, vol. 97, no. 2, pp. 255-268, 1988.

[37] G. A. M. Cross and G. B. Takle, "The surface trans-sialidase family of Trypanosoma cruzi," Annual Review of Microbiology, vol. 47, pp. 385-411, 1993.

[38] S. Schenkman, L. P. De Carvalho, and V. Nussenzweig, "Trypanosoma cruzi trans-sialidase and neuraminidase activities can be mediated by the same enzymes," Journal of Experimental Medicine, vol. 175, no. 2, pp. 567-575, 1992.

[39] M. R. S. Briones, C. M. Egima, and S. Schenkman, "Trypanosoma cruzi trans-sialidase gene lacking C-terminal repeats and expressed in epimastigote forms," Molecular and Biochemical Parasitology, vol. 70, no. 1-2, pp. 9-17, 1995.

[40] H. P. Low and R. L. Tarleton, "Molecular cloning of the gene encoding the $83 \mathrm{kDa}$ amastigote surface protein and its identification as a member of the Trypanosoma cruzi sialidase superfamily," Molecular and Biochemical Parasitology, vol. 88, no. 1-2, pp. 137-149, 1997.

[41] M. A. M. Santos, N. Garg, and R. L. Tarleton, "The identification and molecular characterization of Trypanosoma cruzi amastigote surface protein-1, a member of the trans-sialidase gene super-family," Molecular and Biochemical Parasitology, vol. 86, no. 1, pp. 1-11, 1997.

[42] R. Giordano, D. L. Fouts, D. Tewari, W. Colli, J. E. Manning, and M. J. M. Alves, "Cloning of a surface membrane glycoprotein specific for the infective form of Trypanosoma cruzi having adhesive properties to laminin," Journal of Biological Chemistry, vol. 274, no. 6, pp. 3461-3468, 1999.

[43] S. Kahn, T. G. Colbert, J. C. Wallace et al., “The major $85-\mathrm{kDa}$ surface antigen of the mammalian-stage forms of Trypanosoma cruzi is a family of sialidases," Proceedings of the National Academy of Sciences of the United States of America, vol. 88, no. 10, pp. 4481-4485, 1991.

[44] D. L. Fouts, B. J. Ruef, P. T. Ridley, R. A. Wrightsman, D. S. Peterson, and J. E. Manning, "Nucleotide sequence and transcription of a trypomastigote surface antigen gene of Trypanosoma cruzi," Molecular and Biochemical Parasitology, vol. 46, no. 2, pp. 189-200, 1991.

[45] E. Bayer-Santos, C. Aguilar-Bonavides, S. P. Rodrigues et al., "Proteomic analysis of trypanosoma cruzi secretome: characterization of two populations of extracellular vesicles and soluble proteins," Journal of Proteome Research, vol. 12, no. 2, pp. 883-897, 2013.

[46] M. M. G. Teixeira and N. Yoshida, "Stage-specific surface antigens of metacyclic trypomastigotes of Trypanosoma cruzi identified by monoclonal antibodies," Molecular and Biochemical Parasitology, vol. 18, no. 3, pp. 271-282, 1986.

[47] N. Nogueira, "Host and parasite factors affecting the invasion of mononuclear phagocytes by Trypanosoma cruzi," Ciba Foundation symposium, vol. 99, pp. 52-73, 1983.

[48] P. R. C. Correa, E. M. Cordero, L. G. Gentil, E. Bayer-Santos, and J. F. D. Silveira, "Genetic structure and expression of the surface glycoprotein GP82, the main adhesin of Trypanosoma cruzi metacyclic trypomastigotes," The Scientific World Journal, vol. 2013, Article ID 156734, 11 pages, 2013.
[49] L. M. Freitas, S. L. dos Santos, G. F. Rodrigues-Luiz et al., "Genomic analyses, gene expression and antigenic profile of the trans-sialidase superfamily of trypanosoma cruzi reveal an undetected level of complexity," PLOS ONE, vol. 6, no. 10, Article ID e25914, 2011.

[50] I. C. Cuevas, J. J. Cazzulo, and D. O. Sánchez, "gp63 homologues in Trypanosoma cruzi: surface antigens with metalloprotease activity and a possible role in host cell infection," Infection and Immunity, vol. 71, no. 10, pp. 5739-5749, 2003.

[51] M. S. Llewellyn, L. A. Messenger, A. O. Luquetti et al., "Deep sequencing of the trypanosoma cruzi GP63 surface proteases reveals diversity and diversifying selection among chronic and congenital chagas disease patients," PLoS Neglected Tropical Diseases, vol. 9, no. 4, Article ID e0003458, 2015.

[52] M. M. Kulkarni, C. L. Olson, D. M. Engman, and B. S. McGwire, "Trypanosoma cruzi GP63 proteins undergo stage-specific differential posttranslational modification and are important for host cell infection," Infection and Immunity, vol. 77, no. 5, pp. 2193-2200, 2009.

[53] M. M. Kangussu-Marcolino, R. M. C. De Paiva, P. R. Araújo et al., "Distinct genomic organization, mRNA expression and cellular localization of members of two amastin sub-families present in Trypanosoma cruzi," BMC Microbiology, vol. 13, no. 1, article 10, 2013.

[54] E. A. García, M. Ziliani, F. Agüero, G. Bernabó, D. O. Sánchez, and V. Tekiel, "TcTASV: a novel protein family in Trypanosoma cruzi identified from a subtractive trypomastigote cDNA library," PLoS Neglected Tropical Diseases, vol. 4, no. 10, article e841, 2010.

[55] G. Bernabó, G. Levy, M. Ziliani, L. D. Caeiro, D. O. Sánchez, and V. Tekiel, "TcTASV-C, a protein family in trypanosoma cruzi that is predominantly trypomastigote-stage specific and secreted to the medium," PLOS ONE, vol. 8, no. 7, Article ID e71192, 2013.

[56] F. C. G. Dos Reis, W. A. S. Júdice, M. A. Juliano, L. Juliano, J. Scharfstein, and A. P. C. De A. Lima, "The substrate specificity of cruzipain 2, a cysteine protease isoform from Trypanosoma cruzi," FEMS Microbiology Letters, vol. 259, no. 2, pp. 215-220, 2006.

[57] E. D. Nery, M. A. Juliano, M. Meldal et al., "Characterization of the substrate specificity of the major cysteine protease (cruzipain) from Trypanosoma cruzi using a portion-mixing combinatorial library and fluorogenic peptides," Biochemical Journal, vol. 323, no. 2, pp. 427-433, 1997.

[58] A. E. Eakin, A. A. Mills, G. Harth, J. H. Mckerrow, and C. S. Craik, "The sequence, organization, and expression of the major cysteine protease (cruzain) from Trypanosoma cruzi," The Journal of Biological Chemistry, vol. 267, no. 11, pp. 7411-20, 1992.

[59] W. A. S. Judice, M. H. S. Cezari, A. P. C. A. Lima et al., "Comparison of the specificity, stability and individual rate constants with respective activation parameters for the peptidase activity of cruzipain and its recombinant form, cruzain, from Trypanosoma cruzi," European Journal of Biochemistry, vol. 268, no. 24, pp. 6578-6586, 2001.

[60] A. C. C. Frasch, "Functional diversity in the trans-sialidase and mucin families in Trypanosoma cruzi," Parasitology Today, vol. 16, no. 7, pp. 282-286, 2000.

[61] S. Schenkman, D. Eichinger, M. E. A. Pereira, and V. Nussenzweig, "Structural and functional properties of Trypanosoma trans-sialidase," Annual Review of Microbiology, vol. 48, pp. 499-523, 1994. 
[62] W. Colli, “Trans-sialidase: a unique enzyme activity discovered in the protozoan Trypanosoma cruzi," FASEB Journal, vol. 7, no. 13, pp. 1257-1264, 1993.

[63] N. Yoshida, R. A. Mortara, M. F. Araguth, J. C. Gonzalez, and M. Russo, "Metacyclic neutralizing effect of monoclonal antibody 10D8 directed to the 35- and 50-kilodalton surface glycoconjugates of Trypanosoma cruzi," Infection and Immunity, vol. 57, no. 6, pp. 1663-1667, 1989.

[64] G. E. Cánepa, A. C. Mesías, H. Yu, X. Chen, and C. A. Buscaglia, "Structural features affecting trafficking, processing, and secretion of Trypanosoma cruzi mucins," Journal of Biological Chemistry, vol. 287, no. 31, pp. 26365-26376, 2012.

[65] I. C. Almeida and R. T. Gazzinelli, "Proinflammatory activity of glycosylphosphatidylinositol anchors derived from Trypanosoma cruzi: structural and functional analyses," Journal of Leukocyte Biology, vol. 70, no. 4, pp. 467-477, 2001.

[66] A. Acosta-Serrano, I. C. Almeida, L. H. Freitas-Junior, N. Yoshida, and S. Schenkman, "The mucin-like glycoprotein super-family of Trypanosoma cruzi: structure and biological roles," Molecular and Biochemical Parasitology, vol. 114, no. 2, pp. 143-150, 2001.

[67] J. M. Di Noia, I. D’Orso, D. O. Sánchez, and A. C. C. Frasch, “AUrich elements in the 3'-untranslated region of a new mucin-type gene family of Trypanosoma cruzi confers mRNA instability and modulates translation efficiency," Journal of Biological Chemistry, vol. 275, no. 14, pp. 10218-10227, 2000.

[68] V. A. Campo, C. A. Buscaglia, J. M. Di Noia, and A. C. C. Frasch, "Immunocharacterization of the mucin-type proteins from the intracellular stage of Trypanosoma cruzi," Microbes and Infection, vol. 8, no. 2, pp. 401-409, 2006.

[69] M. V. Han and C. M. Zmasek, "PhyloXML: XML for evolutionary biology and comparative genomics," BMC Bioinformatics, vol. 10, article 356, 2009.

[70] J. M. Di Noia, G. D. Pollevick, M. T. Xavier et al., "High diversity in mucin genes and mucin molecules in Trypanosoma cruzi," The Journal of Biological Chemistry, vol. 271, no. 50, pp. 3207832083, 1996.

[71] E. Barreto-Bergter and A. B. Vermelho, "Structures of glycolipids found in trypanosomatids: contribution to parasite functions," Open Parasitology Journal, vol. 4, no. 1, pp. 84-97, 2010.

[72] J. M. Di Noia, C. A. Buscaglia, C. R. De Marchi, I. C. Almeida, and A. C. C. Frasch, "A Trypanosoma cruzi small surface molecule provides the first immunological evidence that Chagas' disease is due to a single parasite lineage," Journal of Experimental Medicine, vol. 195, no. 4, pp. 401-413, 2002.

[73] C. A. Buscaglia and J. M. Di Noia, "Trypanosoma cruzi clonal diversity and the epidemiology of Chagas' disease," Microbes and Infection, vol. 5, no. 5, pp. 419-427, 2003.

[74] C. R. De Marchi, J. M. Di Noia, A. C. C. Frasch, V. A. Neto, I. C. Almeid, and C. A. Buscaglia, "Evaluation of a recombinant Trypanosoma cruzi mucin-like antigen for serodiagnosis of Chagas' disease," Clinical and Vaccine Immunology, vol. 18, no. 11, pp. 1850-1855, 2011.

[75] E. S. Nakayasu, D. V. Yashunsky, L. L. Nohara, A. C. T. Torrecilhas, A. V. Nikolaev, and I. C. Almeida, "GPIomics: global analysis of glycosylphosphatidylinositol-anchored molecules of Trypanosoma cruzi," Molecular Systems Biology, vol. 5, article 261, 2009.

[76] L. M. De Pablos and A. Osuna, "Conserved regions as markers of different patterns of expression and distribution of the mucin-associated surface proteins of Trypanosoma cruzi," Infection and Immunity, vol. 80, no. 1, pp. 169-174, 2012.

[77] U. Frevert, S. Schenkman, and V. Nussenzweig, "Stage-specific expression and intracellular shedding of the cell surface transsialidase of Trypanosoma cruzi," Infection and Immunity, vol. 60, no. 6, pp. 2349-2360, 1992.

[78] R. R. Moraes Barros, M. M. Marini, C. R. Antônio et al., "Anatomy and evolution of telomeric and subtelomeric regions in the human protozoan parasite Trypanosoma cruzi," BMC Genomics, vol. 13, no. 1, article 229, 2012.

[79] S. Schenkman, M.-S. Jiang, G. W. Hart, and V. Nussenzweig, "A novel cell surface trans-sialidase of Trypanosoma cruzi generates a stage-specific epitope required for invasion of mammalian cells," Cell, vol. 65, no. 7, pp. 1117-1125, 1991.

[80] M. E. A. Pereira, M. A. Loures, F. Villalta, and A. F. B. Andrade, "Lectin receptors as markers for Trypanosoma cruzi. Developmental stages and a study of the interaction of wheat germ agglutinin with sialic acid residues on epimastigote cells," Journal of Experimental Medicine, vol. 152, no. 5, pp. 1375-1392, 1980.

[81] J. O. Previato, A. F. B. Andrade, M. C. V. Pessolani, and L. Mendonca-Previato, "Incorporation of sialic acid into Trypanosoma cruzi macromolecules: a proposal for a new metabolic route," Molecular and Biochemical Parasitology, vol. 16, no. 1, pp. 85-96, 1985.

[82] B. Zingales, C. Carniol, R. M. de Lederkremer, and W. Colli, "Direct sialic acid transfer from a protein donor to glycolipids of trypomastigote forms of Trypanosoma cruzi," Molecular and Biochemical Parasitology, vol. 26, no. 1-2, pp. 135-144, 1987.

[83] R. P. Prioli, I. Rosenberg, and M. E. A. Pereira, "High- and lowdensity lipoproteins enhance infection of Trypanosoma cruzi in vitro," Molecular and Biochemical Parasitology, vol. 38, no. 2, pp. 191-198, 1990.

[84] S. Tomlinson, L. C. Pontes de Carvalho, F. Vandekerckhove, and V. Nussenzweig, "Role of sialic acid in the resistance of Trypanosoma cruzi trypomastigotes to complement," Journal of Immunology, vol. 153, no. 7, pp. 3141-3147, 1994.

[85] V. L. Pereira-Chioccola, A. Acosta-Serrano, I. Correia de Almeida et al., "Mucin-like molecules form a negatively charged coat that protects Trypanosoma cruzi trypomastigotes from killing by human anti- $\alpha$-galactosyl antibodies," Journal of Cell Science, vol. 113, part 7, pp. 1299-1307, 2000.

[86] K. Nagamune, A. Acosta-Serrano, H. Uemura et al., "Surface sialic acids taken from the host allow trypanosome survival in Tsetse fly vectors," Journal of Experimental Medicine, vol. 199, no. 10, pp. 1445-1450, 2004.

[87] T. Jacobs, H. Erdmann, and B. Fleischer, "Molecular interaction of Siglecs (sialic acid-binding Ig-like lectins) with sialylated ligands on Trypanosoma cruzi," European Journal of Cell Biology, vol. 89, no. 1, pp. 113-116, 2010.

[88] N. Yoshida, M. L. Dorta, A. T. Ferreira et al., "Removal of sialic acid from mucin-like surface molecules of Trypanosoma cruzi metacyclic trypomastigotes enhances parasite-host cell interaction," Molecular and Biochemical Parasitology, vol. 84, no. 1, pp. 57-67, 1997.

[89] G. D. Pollevick, J. Affranchino, A. C. C. Frasch, and D. O. Sánchez, "The complete sequence of a shed acute-phase antigen of Trypanosoma cruzi," Molecular and Biochemical Parasitology, vol. 47, no. 2, pp. 247-250, 1991.

[90] C. A. Buscaglia, J. Alfonso, O. Campetella et al., “Tandem amino acid repeats from Trypanosoma cruzi shed antigens increase the 
half-life of proteins in blood," Blood, vol. 93, no. 6, pp. 20252032, 1999.

[91] S. S. C. Rubin-de-Celis, H. Uemura, N. Yoshida, and S. Schenkman, "Expression of trypomastigote trans-sialidase in metacyclic forms of Trypanosoma cruzi increases parasite escape from its parasitophorous vacuole," Cellular Microbiology, vol. 8, no. 12, pp. 1888-1898, 2006.

[92] M. A. Ouaissi, J. P. Kusnierz, H. Gras-masse et al., "Fluorescence-activated cell-sorting analysis of fibronectin peptides binding to trypanosoma cruzi trypomastigotes," The Journal of Protozoology, vol. 35, no. 1, pp. 111-114, 1988.

[93] C. Claser, N. M. Espíndola, G. Sasso, A. J. Vaz, S. B. Boscardin, and M. M. Rodrigues, "Immunologically relevant strain polymorphism in the Amastigote Surface Protein 2 of Trypanosoma cruzi," Microbes and Infection, vol. 9, no. 8, pp. 1011-1019, 2007.

[94] W. Colli and M. J. M. Alves, "Relevant glycoconjugates on the surface of trypanosoma cruzi," Memórias do Instituto Oswaldo Cruz, vol. 94, no. 1, pp. 37-49, 1999.

[95] O. Campetella, D. Sánchez, J. J. Cazzulo, and A. C. C. Frasch, "A superfamily of trypanosoma cruzi surface antigens," Parasitology Today, vol. 8, no. 11, pp. 378-381, 1992.

[96] B. Wizel, M. Nunes, and R. L. Tarleton, "Identification of Trypanosoma cruzi trans-sialidase family members as targets of protective CD8+ TC1 responses," Journal of Immunology, vol. 159, no. 12, pp. 6120-6130, 1997.

[97] B. Wizel, M. Palmieri, C. Mendoza et al., "Human infection with Trypanosoma cruzi induces parasite antigen-specific cytotoxic T lymphocyte responses," Journal of Clinical Investigation, vol. 102, no. 5, pp. 1062-1071, 1998.

[98] S. Kahn, M. Wleklinski, A. Aruffo, A. Farr, D. Coder, and M. Kahn, "Trypanosoma cruzi amastigote adhesion to macrophages is facilitated by the mannose receptor," Journal of Experimental Medicine, vol. 182, no. 5, pp. 1243-1258, 1995.

[99] N. A. Peterslund, C. Koch, J. C. Jensenius, and S. Thiel, "Association between deficiency of mannose-binding lectin and severe infections after chemotherapy," Lancet, vol. 358, no. 9282, pp. 637-638, 2001.

[100] I. D. S. Cestari, I. Evans-Osses, J. C. Freitas, J. M. Inal, and M. I. Ramirez, "Complement C2 receptor inhibitor trispanning confers an increased ability to resist complement-mediated lysis in Trypanosoma cruzi," Journal of Infectious Diseases, vol. 198, no. 9, pp. 1276-1283, 2008.

[101] M. H. Magdesian, R. Giordano, H. Ulrich et al., "Infection by Trypanosoma cruzi: identification of a parasite ligand and its host cell receptor," The Journal of Biological Chemistry, vol. 276, no. 22, pp. 19382-19389, 2001.

[102] R. R. Tonelli, R. J. Giordano, E. M. Barbu et al., "Role of the gp85/trans-sialidases in Trypanosoma cruzi tissue tropism: preferential binding of a conserved peptide motif to the vasculature in vivo," PLoS Neglected Tropical Diseases, vol. 4, no. 11, article e864, 2010.

[103] E. M. Cordero, L. G. Gentil, G. Crisante et al., "Expression of GP82 and GP90 surface glycoprotein genes of Trypanosoma cruzi during in vivo metacyclogenesis in the insect vector Rhodnius prolixus," Acta Tropica, vol. 105, no. 1, pp. 87-91, 2008.

[104] M. I. Ramirez, R. De Cassia Ruiz, J. E. Araya et al., "Involvement of the stage-specific 82-kilodalton adhesion molecule of Trypanosoma cruzi metacyclic trypomastigotes in host cell invasion," Infection and Immunity, vol. 61, no. 9, pp. 3636-3641, 1993.

[105] R. C. Ruiz, J. Favoreto S., M. L. Dorta et al., "Infectivity of Trypanosoma cruzi strains is associated with differential expression of surface glycoproteins with differential $\mathrm{Ca} 2+$ signalling activity," Biochemical Journal, vol. 330, no. 1, pp. 505511, 1998.

[106] S. Favoreto Jr., M. L. Dorta, and N. Yoshida, “Trypanosoma cruzi $175-\mathrm{kDa}$ protein tyrosine phosphorylation is associated with host cell invasion," Experimental Parasitology, vol. 89, no. 2, pp. 188-194, 1998.

[107] T. K. Matsumoto, P. C. Cotrim, J. F. Da Silveira, A. M. S. Stolf, and E. S. Umezawa, "Trypanosoma cruzi: Isolation of an immunodominant peptide of TESA (trypomastigote excretedsecreted antigens) by gene cloning," Diagnostic Microbiology and Infectious Disease, vol. 42, no. 3, pp. 187-192, 2002.

[108] M. Beucher and K. A. Norris, "Sequence diversity of the Trypanosoma cruzi complement regulatory protein family," Infection and Immunity, vol. 76, no. 2, pp. 750-758, 2008.

[109] T. L. Kipnis, J. R. David, C. A. Alper, A. Sher, and W. D. da Silva, "Enzymatic treatment transforms trypomastigotes of Trypanosoma cruzi into activators of alternative complement pathway and potentiates their uptake by macrophages," Proceedings of the National Academy of Sciences of the United States of America, vol. 78, no. 1, pp. 602-605, 1981.

[110] M. Berrizbeitia, M. Ndao, J. Bubis et al., "Purified excretedsecreted antigens from Trypanosoma cruzi trypomastigotes as tools for diagnosis of Chagas' disease," Journal of Clinical Microbiology, vol. 44, no. 2, pp. 291-296, 2006.

[111] M. S. Cetron, R. Hoff, S. Kahn, H. Eisen, and W. C. Van Voorhis, "Evaluation of recombinant trypomastigote surface antigens of Trypanosoma cruzi in screening sera from a population in rural Northeastern Brazil endemic for chagas' disease," Acta Tropica, vol. 50, no. 3, pp. 259-266, 1992.

[112] E. E. Jazin, L. Åslund, J. Henriksson, and U. Pettersson, "Trypanosoma cruzi exoantigen is a member of a $160 \mathrm{kDa}$ gene family," Parasitology, vol. 110, no. 1, pp. 61-69, 1995.

[113] K. A. Norris, J. E. Schrimpf, and M. J. Szabo, "Identification of the gene family encoding the 160-kilodalton Trypanosoma cruzi complement regulatory protein," Infection and Immunity, vol. 65, no. 2, pp. 349-357, 1997.

[114] W. C. Van Voorhis, L. Schlekewy, and H. L. Trong, "Molecular mimicry by Trypanosoma cruzi: the F1-160 epitope that mimics mammalian nerve can be mapped to a 12 -amino acid peptide," Proceedings of the National Academy of Sciences of the United States of America, vol. 88, no. 14, pp. 5993-5997, 1991.

[115] L. Freire-De-Lima, L. M. Fonseca, T. Oeltmann, L. MendoncąPreviato, and J. O. Previato, "The trans-sialidase, the major Trypanosoma cruzi virulence factor: three decades of studies," Glycobiology, vol. 25, no. 11, pp. 1142-1149, 2015.

[116] M. H. Branquinha, A. B. Vermelho, S. Goldenberg, and M. C. Bonaldo, "Ubiquity of cysteine- and metalloproteinase activities in a wide range of trypanosomatids," Journal of Eukaryotic Microbiology, vol. 43, no. 2, pp. 131-135, 1996.

[117] F. B. Nogueira, M. A. Krieger, P. Nirdé, S. Goldenberg, A. J. Romanha, and S. M. F. Murta, "Increased expression of ironcontaining superoxide dismutase-A (TcFeSOD-A) enzyme in Trypanosoma cruzi population with in vitro-induced resistance to benznidazole," Acta Tropica, vol. 100, no. 1-2, pp. 119-132, 2006.

[118] A. L. S. D. Santos, R. M. D. A. Soares, C. S. Alviano, and L. F. Kneipp, "Heterogeneous production of metallo-type peptidases in parasites belonging to the family Trypanosomatidae," European Journal of Protistology, vol. 44, no. 2, pp. 103-113, 2008.

[119] N. M. A. El-Sayed and J. E. Donelson, "African trypanosomes have differentially expressed genes encoding homologues of 
the Leishmania GP63 surface protease," Journal of Biological Chemistry, vol. 272, no. 42, pp. 26742-26748, 1997.

[120] P. M. Grandgenett, B. C. Coughlin, L. V. Kirchhoff, and J. E. Donelson, "Differential expression of GP63 genes in Trypanosoma cruzi," Molecular and Biochemical Parasitology, vol. 110, no. 2, pp. 409-415, 2000.

[121] S. M. R. Teixeira, D. G. Russell, L. V. Kirchhoff et al., "A differentially expressed gene family encoding 'amastin, a surface protein of Trypanosoma cruzi amastigotes," Journal of Biological Chemistry, vol. 269, no. 32, pp. 20509-20516, 1994.

[122] A. P. Jackson, "The evolution of amastin surface glycoproteins in trypanosomatid parasites," Molecular Biology and Evolution, vol. 27, no. 1, pp. 33-45, 2010.

[123] A. Rochette, F. McNicoll, J. Girard et al., "Characterization and developmental gene regulation of a large gene family encoding amastin surface proteins in Leishmania spp.," Molecular and Biochemical Parasitology, vol. 140, no. 2, pp. 205-220, 2005.

[124] H. Azizi, K. Hassani, Y. Taslimi, H. S. Najafabadi, B. Papadopoulou, and S. Rafati, "Searching for virulence factors in the non-pathogenic parasite to humans Leishmania tarentolae," Parasitology, vol. 136, no. 7, pp. 723-735, 2009.

[125] G. C. Cerqueira, D. C. Bartholomeu, W. D. DaRocha et al., "Sequence diversity and evolution of multigene families in Trypanosoma cruzi," Molecular and Biochemical Parasitology, vol. 157, no. 1, pp. 65-72, 2008.

[126] T. A. Minning, D. B. Weatherly, J. Atwood III, R. Orlando, and R. L. Tarleton, "The steady-state transcriptome of the four major life-cycle stages of Trypanosoma cruzi," BMC Genomics, vol. 10, article 370, 2009.

[127] M. C. Cruz, N. Souza-Melo, C. V. da Silva et al., "Trypanosoma cruzi: role of $\delta$-amastin on extracellular amastigote cell invasion and differentiation," PLoS ONE, vol. 7, no. 12, Article ID e51804, 2012.

[128] J. A. Atwood III, D. B. Weatherly, T. A. Minning et al., "Microbiology: the Trypanosoma cruzi proteome," Science, vol. 309, no. 5733, pp. 473-476, 2005.

[129] N. M. El-Sayed, P. J. Myler, G. Blandin et al., "Comparative genomics of trypanosomatid parasitic protozoa," Science, vol. 309, no. 5733, pp. 404-409, 2005.

[130] D. C. Bartholomeu, G. C. Cerqueira, A. C. A. Leão et al., "Genomic organization and expression profile of the mucin-associated surface protein (masp) family of the human pathogen Trypanosoma cruzi," Nucleic Acids Research, vol. 37, no. 10, pp. 3407-3417, 2009.

[131] L. M. De Pablos, G. G. González, J. S. Parada et al., "Differential expression and characterization of a member of the mucinassociated surface protein family secreted by Trypanosoma cruzi," Infection and Immunity, vol. 79, no. 10, pp. 3993-4001, 2011.

[132] L. M. De Pablos, I. M. Díaz Lozano, M. I. Jercic et al., “The C-terminal region of Trypanosoma cruzi MASPs is antigenic and secreted via exovesicles," Scientific Reports, vol. 6, Article ID 27293, 2016.

[133] C. Serna, J. A. Lara, S. P. Rodrigues, A. F. Marques, I. C. Almeida, and R. A. Maldonado, "A synthetic peptide from Trypanosoma cruzi mucin-like associated surface protein as candidate for a vaccine against Chagas disease," Vaccine, vol. 32, no. 28, pp. 3525-3532, 2014.

[134] M. V. Chuenkova and M. PereiraPerrin, "Chagas' disease parasite promotes neuron survival and differentiation through TrkA nerve growth factor receptor," Journal of Neurochemistry, vol. 91, no. 2, pp. 385-394, 2004.
[135] L. Lima, P. A. Ortiz, F. M. da Silva et al., "Repertoire, genealogy and genomic organization of cruzipain and homologous genes in Trypanosoma cruzi, T. cruzi-like and other Trypanosome species," PLoS ONE, vol. 7, no. 6, Article ID e38385, 2012.

[136] L. Åslund, J. Henriksson, O. Campetella, A. C. C. Frasch, U. Pettersson, and J. J. Cazzulo, "The C-terminal extension of the major cysteine proteinase (cruzipain) from Trypanosoma cruzi," Molecular and Biochemical Parasitology, vol. 45, no. 2, pp. 345-347, 1991.

[137] V. Alvarez, F. Parussini, L. Åslund, and J. J. Cazzulo, "Expression in insect cells of active mature cruzipain from trypanosoma cruzi, containing its c-terminal domain," Protein Expression and Purification, vol. 26, no. 3, pp. 467-475, 2002.

[138] T. Souto-Padron, O. E. Campetella, J. J. Cazzulo et al., "Cysteine proteinase in Trypanosoma cruzi: immunocytochemical localization and involvement in parasite-host cell interaction," Journal of Cell Science, vol. 96, part 3, pp. 485-490, 1990.

[139] M. N. L. Meirelles, L. Juliano, E. Carmona et al., "Inhibitors of the major cysteinyl proteinase (GP57/51) impair host cell invasion and arrest the intracellular development of Trypanosoma cruzi in vitro," Molecular and Biochemical Parasitology, vol. 52, no. 2, pp. 175-184, 1992.

[140] S. Gea, N. Guiñazu, A. Pellegrini et al., "Cruzipain, a major Trypanosoma cruzi cystein protease in the host-parasite interplay," Inmunologia, vol. 25, no. 4, pp. 225-238, 2006.

[141] P. M. Ferrão, C. M. D’Avila-Levy, T. C. Araujo-Jorge et al., "Cruzipain activates latent TGF- $\beta$ from host cells during T. cruzi invasion," PLoS ONE, vol. 10, no. 5, Article ID e0124832, 2015.

[142] G. V. F. Brunoro, M. A. Caminha, A. T. D. S. Ferreira et al., "Reevaluating the Trypanosoma cruzi proteomic map: the shotgun description of bloodstream trypomastigotes," Journal of Proteomics, vol. 115, pp. 58-65, 2015.

[143] S. B. Roberts, J. L. Robichaux, A. K. Chavali et al., "Proteomic and network analysis characterize stage-specific metabolism in Trypanosoma cruzi," BMC Systems Biology, vol. 3, article 52, 2009.

[144] D. Pérez-Morales, H. Lanz-Mendoza, G. Hurtado, R. MartínezEspinosa, and B. Espinoza, "Proteomic analysis of Trypanosoma cruzi epimastigotes subjected to heat shock," Journal of Biomedicine and Biotechnology, vol. 2012, Article ID 902803, 9 pages, 2012.

[145] M. M. Kangussu-Marcolino, A. P. Cunha, A. R. Avila, J.-P. Herman, and W. D. Darocha, "Conditional removal of selectable markers in Trypanosoma cruzi using a site-specific recombination tool: proof of concept," Molecular and Biochemical Parasitology, vol. 198, no. 2, pp. 71-74, 2014.

[146] D. Peng, S. P. Kurup, P. Y. Yao, T. A. Minning, and R. L. Tarleton, "CRISPR-Cas9-mediated single-gene and gene family disruption in Trypanosoma cruzi," mBio, vol. 6, no. 1, Article ID e02097-14, 2015.

[147] N. Lander, Z.-H. Li, S. Niyogi, and R. Docampo, "CRISPR/Cas9induced disruption of paraflagellar rod protein 1 and 2 genes in Trypanosoma cruzi reveals their role in flagellar attachment," mBio, vol. 6, no. 4, Article ID e01012-15, 2015.

[148] N. Lander, M. A. Chiurillo, M. Storey et al., "CRISPR/Cas9mediated endogenous C-terminal tagging of Trypanosoma cruzi genes reveals the acidocalcisome localization of the inositol 1,4,5-Trisphosphate receptor," Journal of Biological Chemistry, vol. 291, no. 49, pp. 25505-25515, 2016. 

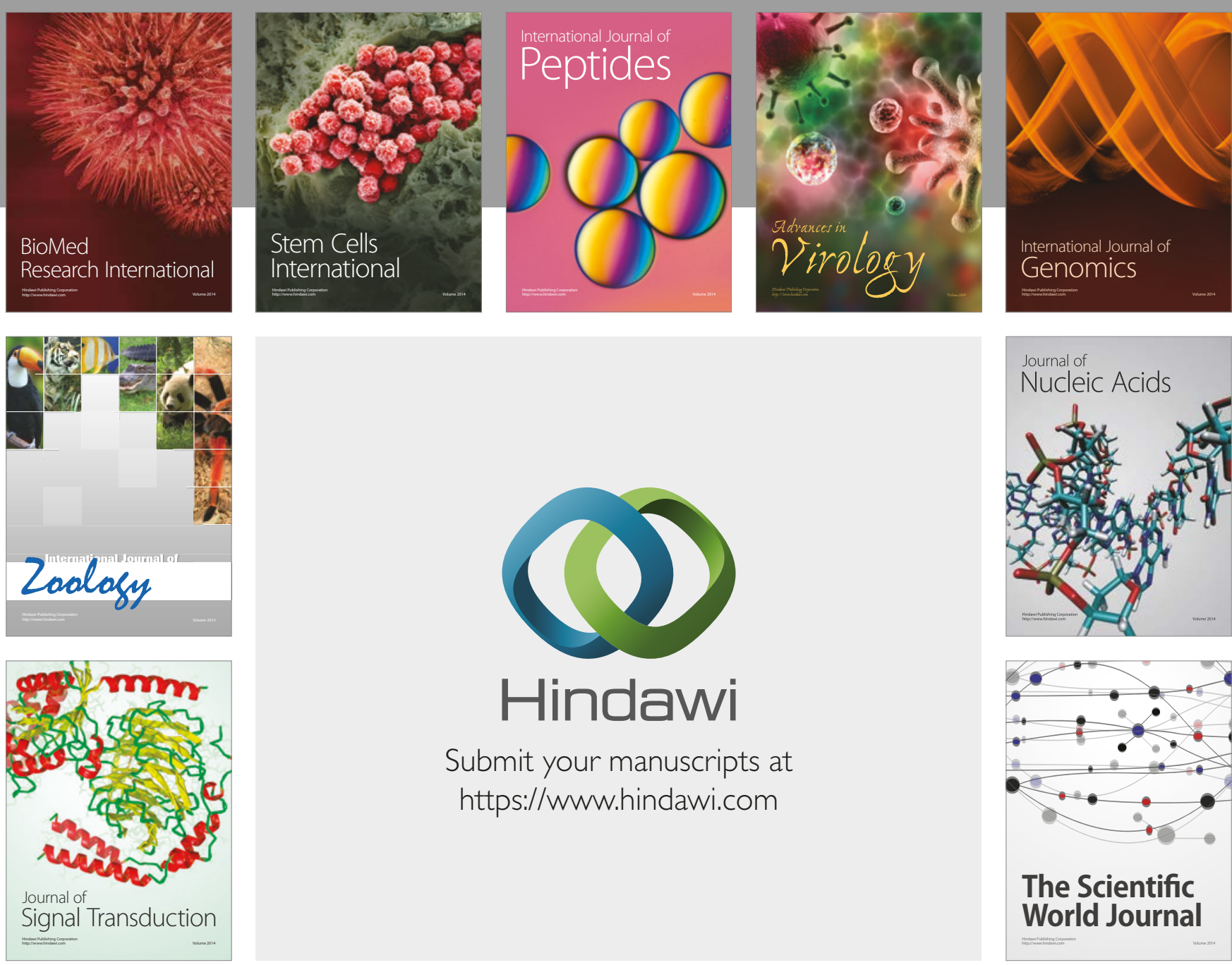

Submit your manuscripts at

https://www.hindawi.com
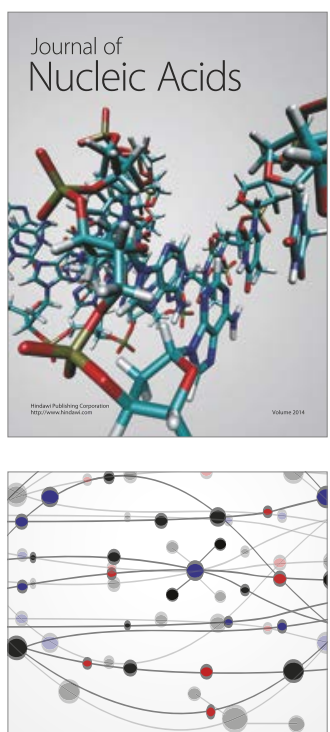

The Scientific World Journal

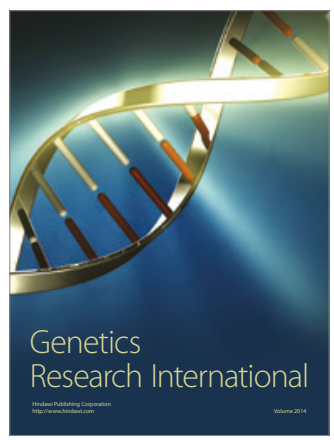

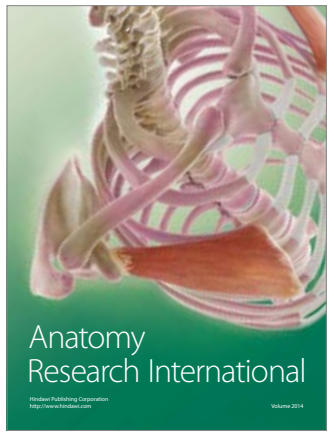

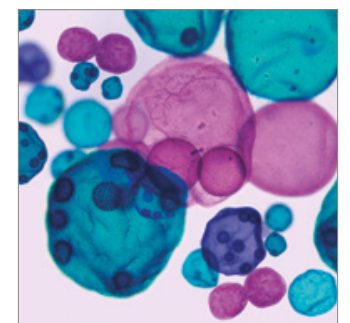

International Journal of Microbiology
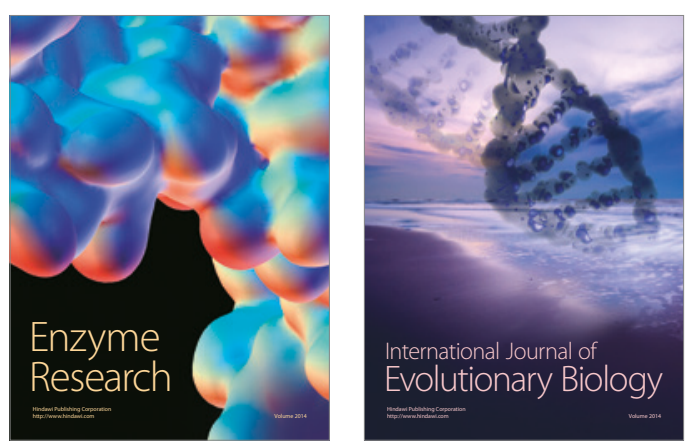
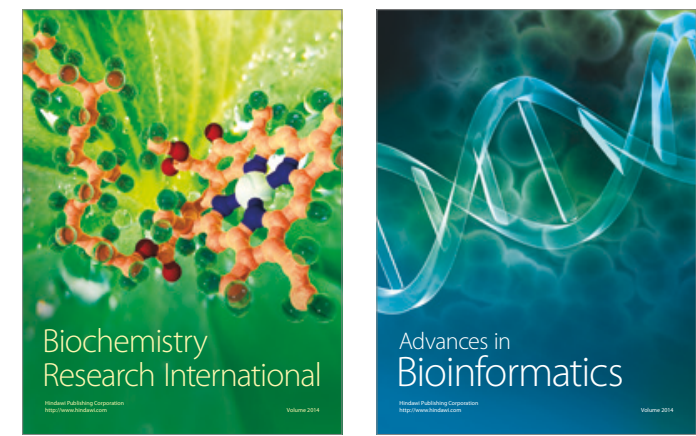

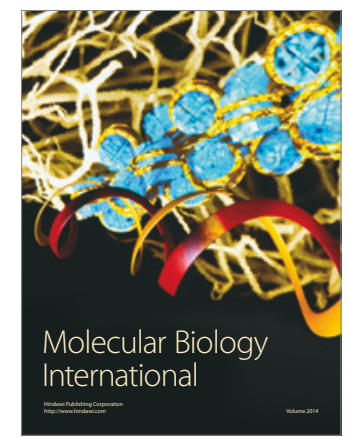

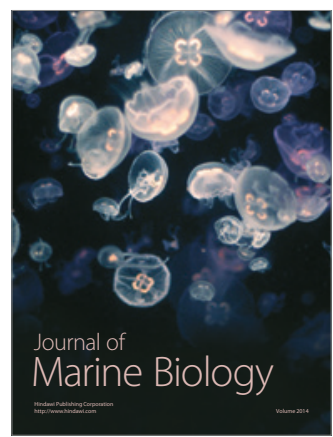

